\title{
A BUSCA PELA REALIZAÇÃO DA DIGNIDADE DA PESSOA HUMANA NO INSTITUTO DA ADOÇÃO
}

\author{
Sarah Carolina Colorado Borges, Ana Augusta Rodrigues Westin Ebaid \\ Universidade do Oeste Paulista - UNOESTE, Presidente Prudente, SP. E-mail: sarah.cborges@hotmail.com
}

\section{RESUMO}

O instituto da adoção sofreu ao longo dos anos inúmeras modificações, e a partir da Constituição Federal de 1988 foi quando as inovações mais importantes começaram a entrar em vigor. A partir desse momento, a adoção começou a ganhar uma nova significativa roupagem para a proteção do direito das crianças e adolescentes. No presente trabalho, através de pesquisas doutrinárias e jurisprudenciais, por meio de livros e artigos, tem a finalidade de fazer uma análise do histórico e processo da adoção que é um assunto sempre muito pertinente e discutido na sociedade, trazendo aspectos positivos, como as inovações que mudaram o foco dos pretendentes para os menores, e trouxeram uma maior garantia aos seus direitos; e aspectos negativos como os preconceitos, adoção tardia e a lentidão do nosso ordenamento jurídico. A metodologia incluiu levantamento bibliográfico. O foco principal é analisar o processo da adoção com base nos princípios da dignidade da pessoa humana encontrados em nossa Carta Magna, e os princípios que regem o instituto da adoção, e como isso tem sido aplicado no dia-a-dia das crianças e adolescentes, para assegurar seus direitos fundamentais e a convivência familiar.

Palavras-chaves: adoção, morosidade, adoção tardia, convivência familiar

\section{THE SEARCH FOR REALIZING THE DIGNITY OF THE HUMAN PERSON IN THE ADOPTION INSTITUTE}

\begin{abstract}
The adoption institute has undergone numerous changes over the years, and from the 1988 Federal Constitution onwards, the most important innovations began to take effect. From that moment on, the adoption began to gain a significant new guise to protect the rights of children and adolescents. In the present work, through doctrinal and jurisprudential research, through books and articles, it aims to make an analysis of the history and adoption process, which is a subject that is always very relevant and discussed in society, bringing positive aspects, such as innovations. who shifted the focus from suitors to minors, and brought a greater guarantee to their rights; and negative aspects such as prejudices, late adoption and the slowness of our legal system. The methodology included bibliographic survey. The main focus is to analyze the adoption process based on the principles of human dignity found in our Charter, and the principles that govern the adoption institute, and how it has been applied in the daily lives of children and adolescents, to ensure their fundamental rights and family life.
\end{abstract}

Keywords: adoption, morosity, late adoption, family living

\section{INTRODUÇÃO}

Ao longo das décadas em nosso país, existiram diversas normas jurídicas regularizando a composição familiar e as filiações. A adoção foi introduzida no nosso ordenamento pelo Código Civil e é aperfeiçoada com a Constituição Federal.

Com o passar dos anos, a linha humanitária foi se fazendo mais presente no tocante a adoção para que assim houvesse 
diminuição das crianças abandonadas encontradas fora de um âmbito familiar e o interesse de criança e adolescente se tornou prioridade.

Apesar da mudança proposta com a Constituição Federal de 1988 e do Estatuto da Criança e do Adolescente, a priorização dos interesses das crianças e adolescentes, o processo de adoção tem-se mostrado lento, acarretando consequências como, desistência da família adotante, criança prejudicada no seu desenvolvimento, ferindo os princípios da dignidade da pessoa humana.

No instituto da adoção a problemática da idade da criança é presente, onde o menor com mais de 3 anos de idade já é considerado "velho" para ser adotado. Existe um interesse muito maior em crianças recém-nascidas e bebês, por diversos fatores. As inovações legislativas que ocorreram até chegarmos no Código Civil/02, Estatuto da Criança e do Adolescente e a Constituição Federal/88, objetivaram acelerar os processos. Contudo, a tentativa de melhora no processo, se mantém atrelado à burocracia do judiciário Brasileiro.

Por essas razões, apresenta o presente trabalho, para fazer uma análise com discussão jurídica que possa contribuir, no assunto da demora dos processos judiciais e as burocracias existentes para a adoção, vez que a adoção tardia de crianças e adolescentes prejudicam a convivência familiar e fere sua dignidade como pessoa humana.

\section{METODOLOGIA}

Consiste em um levantamento bibliográfico, buscando uma análise do tema por meio de obras já publicadas, fazendo uma reflexão de ideias. O método utilizado foi 0 hipotético-dedutivo.

Para a realização desse artigo foram utilizados a leitura de artigos, doutrinas, legislações e demais meios que se mostraram úteis e tocante ao tema proposto.

\section{HISTÓRICO DA ADOÇÃO CONCEITOS DO INSTITUTO DA ADOÇÃO}

$O$ instituto da adoção é possível ser observado desde os tempos mais remotos da história da humanidade e passou por uma evolução única.

Carlos Roberto Gonçalves (2014, p. 381), brilhantemente define:
Adoção é o ato jurídico solene pelo qual alguém recebe em sua família, na qualidade de filho, pessoa a ela estranha.

Já a Maria Helena Diniz (2009, p. 520), faz uma junção de definições:

Adoção é o ato jurídico
solene pelo qual,
observados os requisitos
legais, alguém estabelece,
independentemente de
qualquer relação de
parentesco consanguíneo
ou afim, um vínculo fictício
de filiação, trazendo para
sua família, na condição
de filho, pessoa que,
geralmente, Ihe é
estranha.

O Código de Hamurabi (criado, aproximadamente, no ano de 1772 a.C.), foi o primeiro documento que tratou sobre o assunto da adoção e a Bíblia é considerada o segundo documento. Em relação às suas histórias, Souza (1973, p. 15 e 16), decorre:

O caso mais falado da adoção é inclusive trazido pela Bíblia, aconteceu no Egito, o de Moisés que foi adotado pela filha de Faraó, em uma época que o Faraó estava matando todas as crianças nascidas do sexo masculino, e a mãe de Moisés para proteger a criança o colocou no rio em um cesto, este que foi encontrada pela filha de Faraó, sua mãe adotiva, que o cuidou até crescer.

Muitos estudiosos acreditam que a adoção nasceu de uma necessidade religiosa. $\mathrm{Na}$ Idade Média, século XVI, esse instituto entrou em decadência, por ser algo que não interessava os nobres e por muito tempo, o instituto da adoção foi criado somente com o propósito de satisfazer as pessoas que desejavam adotar.

A adoção passou a ter uma maior importância na época da 1ạ Guerra Mundial, dando respaldo aos órfãos resultantes da guerra. Descentralizou a proteção da pessoa adotante, para a criança adotada. Assim, no final do século 
XIX e início do século XX, no Brasil, a preocupação com crianças abandonadas, aumentaram.

Nas situações em que as crianças não contemplam seu direito de convivência familiar pelos laços sanguíneos, o instituto da adoção se faz presente na tentativa de garantir a realização de seus direitos fundamentais, para que tenham um desenvolvimento digno.

A adoção, hoje em dia, não se baseia mais em um ato contratual, mas garantir a doutrina da proteção integral, visando o melhor interesse da a criança e adolescente.

\section{ORIGEM NA LEGISLAÇÃO BRASILEIRA}

Anteriormente ao século $\mathrm{XX}$, a adoção não possuía regulamento jurídico no Brasil, e foi introduzido pelo Direito Português. Eram regidos no que diz respeito pelo direito romano, como secundário e somente quem não tinha filhos legítimos, podia adotar.

No Brasil, o instituto da adoção tem visibilidade nos anos de 1693, quando vigorou a Lei ao Desamparo de crianças abandonadas. 0 Estado não possuía condições de cuidar delas, então tentava se livrar dessa obrigação.

Foi criada a Roda dos Expostos com o objetivo de diminuir as crianças abandonadas. Existem relatos de como funcionava, a autora Maria Luiz Marcilio explica:

De forma cilíndrica e com uma divisória no meio, esse dispositivo era fixado no muro ou na janela da instituição. No tabuleiro inferior da parte externa, o expositor colocava a criança que enjeitava, girava a Roda e puxava um cordão com uma sineta para avisar à vigilante - ou Rodeira - que um bebê acabara de ser abandonado, retirando-se furtivamente do local, sem ser reconhecido.

Na cidade de São Paulo, no paredão da rua D. Veridiana era onde atuava a roda da Santa Casa de Misericórdia e teve sua efetiva extinção no ano de 1948.

Foi apenas no Código Civil de 1916 em que se encontra a primeira regulamentação jurídica sobre a matéria, onde os adotantes não possuíam filhos e deveriam ter mais de 50 anos. Era necessária a diferença de 18 anos entre o adotante e o adotado. A regulamentação era feita através de ato contratual, não havendo interferência do Estado. Era revogável, e a dissolução poderia acontecer por acordo ou a ingratidão do adotado.

O pátrio poder era transferido para a família adotante, porém, o vínculo consanguíneo continuava com a família biológica. Além de que, o adotado não tinha direito na sucessão caso possuíssem filhos legítimos. Nesse período, o objetivo da adoção era dar continuidade para a linhagem familiar, excluindo a necessidade e o melhor interesse da criança.

Com a criação da Lei no 3.133/1957, a idade do adotante diminuiu para 30 anos, e a diferença mínima para 16 anos, e permitiu filhos anterior à adoção. A adoção se torna irrevogável, mas em relação à sucessão os filhos adotivos não tinham direitos.

Em 1965, com a Lei no 4.655 foi implementada a legitimação adotiva, caracterizada pela adoção de crianças até 5 anos de idade, encontradas desamparadas. 0 vínculo da criança com a família biológica era revogado e a com a família adotante passava a ter o caráter de filho biológico, com os mesmos direitos do filho legítimo.

O Código de Menores (1979), Lei no 6.697/79, revogou a Lei no 4.655/65, trazendo a adoção plena e a simples. Em que a adoção plena, atribuía a criança adotada com idade menor de 7 anos o caráter de filho biológico. Os interessados na adoção precisavam ter mais de 5 anos de matrimônio e, na data do pedido, pelo menos uma das partes ter mais de 30 anos. A adoção permaneceu irrevogável.

Já a adoção simples, dependia da autorização do juiz, não extinguia o vínculo com a família biológca e estabelecia o parentesco apenas do adotado com o adotante. Nesse caso, a adoção era revogável.

\section{CONSTITUIÇÃO DE 1988}

Foi com a Constituição Federal, que ocorreu a equiparação entre a condição de filho adotivo em relação ao filho biológico, sendo proibida qualquer forma de discriminação, conforme o artigo 227, §6ㅇ.

Acrescentando, a adoção passou a ser irrevogável e irretratável, então, mesmo com a morte dos adotantes ou do adotado, o vínculo não era extinto, o que garantia ao filho adotivo os mesmos direitos a herança, que o filho natural possuía. 


\section{ESTATUTO DA CRIANÇA E DO ADOLESCENTE}

O Estatuto da Criança e do adolescente, Lei no 8.069, entrou em vigor no ano de 1990, e com essa nova lei, passou a ser criança com até 12 anos de idade incompletos e adolescentes com 12 a 18 anos de idade. Criado com objetivo de buscar efetividade ao Princípio da Proteção Integral, regular e garantir o processo de adoção e os direitos envolvidos, inclusive, os sucessórios.

Nesse momento, houve a existência de 2 tipos de adoção. Uma é a adoção estatutária ou plena, que era dirigida pelo Estatuto da Criança e do Adolescente; e a adoção civil, dirigida pelo Código Civil de 1916.

Foi com o Código Civil de 2002, que permaneceu somente a adoção plena, em que o adotado terá caráter de filho biológico, revogado o vínculo com sua família de origem, na forma irrevogável, e garantia dos direitos sucessórios. Na doutrina de Diniz fala muito claro sobre (2010, p.524):

[...] era a espécie de
adoção pela qual o menor
adotado passava a ser,
irrevogavelmente, para
todos os efeitos legais,
filho dos adotantes,
desligando-se de qualquer
vínculo com os pais de
sangue e parentes, salvo
os impedimentos
matrimoniais. Essa
modalidade tinha por fim:
atender o desejo que um
casal tinha de trazer ao
seio da família um menor
que se encontrasse em
determinadas situações
estabelecidas em lei, como
filho e proteger a infância
desvalida, possibilitando
que o menor abandonado
ou órfão tivesse uma
família organizada e
estável.

Essa lei tirou o caráter de negócio jurídico que a adoção possuía. Aconteceu a proteção integral e acolhimento da criança submetida ao processo de adoção. $O$ art. 3o do ECA contém o que é de direito fundamental a esta criança que vem a ser adotada.

Nos dias atuais, o instituto da adoção é gerido, em nosso ordenamento jurídico, pela Lei no $12.010 / 2009$, garantindo que a adoção seja dirigida pelo Estatuto da Criança e do Adolescente.

A Lei Nacional de Adoção, Lei no $12.010 / 09$, surge na tentativa de agilizar o procedimento de adoção e diminuir o período que a criança e adolescente permanece em lares adotivos.

A inovação aconteceu com a criação do Cadastro Nacional de Adoção (CNA), como forma de acelerar o encontro das crianças disponíveis para a adoção com os interessados. Estabeleceu prazos mais curtos, e limitou o prazo de permanência em abrigos por 2 anos.

O Estatuto da Criança e do Adolescente traz a importância da criança e do adolescente ser criado em âmbito familiar e proibiu todos os tipos de preconceitos em relação a maneira de se estabelecer uma família, então um dos direitos mais importantes assegurados pelo legislador é o da Convivência Familiar, seja na família natural ou uma substituta pela adoção.

O maior objetivo da lei da adoção (Lei no 12.010/09), foi proteger o adotado de possível arrependimento da parte adotante, garantindo, assim, a irreversibilidade da adoção. Portanto, tamanha rigidez do processo gerou um instituto ineficiente.

Os perfis cadastrados no CNA divergem com os perfis pretendidos, pois há demora na inclusão desses cadastros e são poucas as famílias que aceitam adotar crianças maiores de quatro anos.

0 art. 50, §3 traz a habilitação prévia, objetivando facilitar a supervisão da "equipe técnica da Justiça da Infância e da Juventude". E o que era para facilitar, acaba dificultando a adoção e desgastando o adotado.

Portanto, ao invés das mudanças protegerem as crianças e adolescentes, elas burocratizaram 0 processo de adoção, provocando uma inviabilidade do instituto no Brasil. Como consequência, muitas famílias se sentiram desestimuladas a encararem o processo de adoção.

O Brasil não teve estruturas para suportar essas mudanças trazidas. Os cadastros regionais, a necessidade de fixar período de estágio de convivência e o período de preparação psicossocial e jurídica são muito demorados.

\section{LEI № 13.509/2017}

Diante de todo o exposto, a Lei no 13.509/17, vem como uma tentativa de trazer um novo ânimo para o instituto da adoção, 
adequando o Estatuto da Criança e do Adolescente à realidade brasileira atual. $O$ artigo "A lei 13.509/2017 e a ressurreição da adoção", pontua de forma interessante:

Diante de tal morosidade, constatou-se, no campo da adoção, um paradoxo que assola muitas leis brasileiras: a falta de efetividade. Pode-se aqui realizar uma analogia com a utilização de uma classificação do campo do Direito Constitucional, cunhada por Karl Loewenstein, que bem descreveria o caso: o nominalismo. De acordo com o autor, o texto constitucional mostra-se nominal quando não reflete a realidade atual do país, por conter preceitos ainda não observados na prática, ou seja, carece de força normativa adequada. $\mathrm{O}$ excesso de zelo almejado acabou causando o desestímulo à adoção, a desistência de adotantes que esperam anos na fila e, portanto, a inefetividade da lei.

Importantes mudanças foram contempladas no art. 46 do Estatuto da Criança e do Adolescente referente ao estágio de convivência. Nesse período será analisado se o menor se adaptará à nova família. Antes, havia um prazo final. Com a nova disposição, o juiz pode fixar um prazo até 90 dias.

Acerca da habilitação, o prazo máximo para concluir é de 120 dias. De acordo com art. 50 do Estatuto da Criança e do Adolescente, cada comarca deve ter um registro de crianças e adolescentes em condições de serem adotados e outro de pessoas interessadas. Para fazer parte do cadastro de adotantes, deverá ser aprovado em procedimento de habilitação.

0 art. 152, §2ㅇ estabeleceu que os prazos e procedimento da Lei no 8.069/90 deverão ser contados em dias corridos e reduziu em 15 dias o prazo do Ministério Público para ajuizar ação de destituição do poder familiar.
No caso em que ambos os pais concordarem com a adoção, é possível a aceitação da colocação do filho em família substituta por requerimento em cartório, tendo como formalidade, a designação de audiência pelo juiz em um prazo máximo de 10 dias.

Contudo, o que era pra ser considerado um avanço e agilidade no ordenamento jurídico para garantir o melhor interesse da criança, acabou se tornando mais burocrático ainda. A nova lei da adoção, regulamenta o instituto como algo excepcional.

Isso quer dizer que, até que a criança seja direcionada para a adoção ela necessita passar por contínuas tentativas de introdução no âmbito da família biológica, seja por tentativas com os próprios pais, ou parentes próximos. $\mathrm{E}$ não houver manifestação de interesse na guarda, aí que se dá início ao processo de destituição do poder familiar.

$E$ as consequências dessa tentativa frustrada para uma criança e um adolescente de inserir no âmbito familiar podem ser irreversíveis, pois a idade que se avança e o sentimento de abandono, tornam difícil a possibilidade de uma futura adoção.

Dessa forma aqui se devem dar uma maior atenção, para o princípio da dignidade da pessoa humana e da convivência familiar, presentes na Constituição Federal/88. Em que, se a família não deseja permanecer com a criança, de prontidão deveria ser feita a tentativa dessa criança ser inserida em outra entidade familiar, antes que se torne uma tentativa tardia.

Para contemplar essas ideias, vale transcrever uma decisão do Tribunal de Justiça de São Paulo em que se faz presente essa nova lei, destacando os seguintes trechos:

A r. sentença recorrida julgou improcedentes os pedidos, ao argumento de que embora a criança mantenha relação de afinidade com o apelante, também nutre sentimento por seu pai biológico e este igualmente pelo filho[...]

As provas dos autos evidenciam não só que a figura de pai é exercida efetivamente pelo ora recorrente, como a existência de 
socioafetividade entre 0 adotante e o adotado[...]

Em outras palavras, a socioafetividade como uma forma alternativa de se ver efetivar os princípios do melhor interesse da criança e da dignidade da pessoa humana.

A referência de figura paterna para ela é o requerente, por quem demonstra nutrir muita afetividade, com um relacionamento pautado pela familiaridade e intimidade, que lhe possibilita experimentar sentimentos de segurança e confiança.

É bom lembrar que as ações judiciais envolvendo os menores devem ser decididas com obediência aos princípios do melhor interesse da criança ou adolescente e de sua proteção integral' ${ }^{1}$. (grifo nosso)

Nesse julgado demonstra-se a importância dessa lei ao garantir o bem-estar e o interesse do menor, por meio da prevalência do vínculo afetivo sobre o laço sanguíneo quando for para promover o direito a convivência familiar, também se fazendo presente os princípios que regem o instituto da adoção e que devem ser assegurados às crianças e adolescentes, como a proteção integral e o melhor interesse.

\section{PROCESSO DE ADOÇÃO}

O processo de adoção, no Brasil, se dá início com o pedido à Vara da Infância e Juventude. A idade mínima para qualificar à adoção é de 18 anos, e a diferença entre adotado e adotante permanece sendo de 16 anos.

Os requisitos que devem estar presentes são: permissão dos pais ou responsável legal, salvo em casos que houver a destituição do poder familiar. E a criança maior de 12 anos, deve consentir também, conforme o artigo 28, §2o do Estatuto da Criança e do Adolescente.

Para iniciar o processo da adoção é necessária uma petição, e após a aprovação, os nomes dos pretendes serão inseridos no Cadastro
Nacional de Adoção. Durantes as entrevistas escolhem o perfil que desejam da criança desejada. Preferencialmente, a legislação prevê que os irmãos não sejam separados, porém, existem casos em que ocorre essa separação.

No caso de uma criança, se enquadrar no perfil pretendido, a Vara da Infância e Juventude comunica os interessados, e se positivo, ocorrerá uma apresentação. Após a criança será entrevistada para que manifeste seu desejo de prosseguir com a adoção. É fixado pelo juiz o período de estágio de convivência e permitido por lei que seja renunciado, se o menor estiver em contato e convívio com os interessados adotantes por um período de tempo considerado satisfatório, para observar a constituição do vínculo entre as partes.

Concluído o processo de adoção, a criança ou o adolescente adotado passara a dispor dos mesmos direitos ao filho biológico.

\section{DIGNIDADE DA PESSOA HUMANA INTERPRETAÇÕES CONSTITUCIONAIS DIGNIDADE DA PESSOA HUMANA}

Os princípios constitucionais possuem um valor universal. Com tamanha relevância, a existência deles no instituto da adoção merece destaque, pois garante que os direitos das crianças e adolescentes não serão desrespeitados.

A dignidade da pessoa humana é um dos fundamentos da República Federativa do Brasil, e um norteador para o estado democrático de direito, conforme o art. 1ํ, III da Constituição Federal.

Nesse sentido, pronuncia-se Maria Berenice Dias (2016, p.48):

Na medida em que a
ordem constitucional
elevou a dignidade da
pessoa humana a
fundamento da ordem
jurídica, houve uma opção
expressa pela pessoa,
ligando todos os institutos
à realização de sua
personalidade. Tal
fenômeno provocou a
despatrimonialização e a
personalização dos
institutos jurídicos, de
modo a colocar a pessoa
humana no centro
protetor do direito.


Considera-se uma condição que antevê o reconhecimento de todos os outros direitos e garantias fundamentais. Alexandre de Moraes (2005, p.129) entende sobre dignidade da pessoa humana:

Trata-se de um valor
moral inerente à pessoa,
que se manifesta
singularmenter na
autodeterminação
consciente e responsável
da própria vida e traz
consigo a pretensão ao
respeito por parte das
demais pessoas,
constituindo-se um
mínimo invulnerável que
todo estatuto jurídico
deve assegurar, de modo
que somente
excepcionalmente possam
ser feitas limitações ao
exercício dos direitos
fundamentais,
sempre sem menosprezar
a necessária estima que
merecem todas as pessoas
enquanto seres humanos.

Legitimado pela Constituição Federal, este fundamento básico se aplica a crianças e adolescentes de forma muito mais veemente, em razão delas estarem em fase de desenvolvimento, traz como um dever da família, da sociedade e do Estado assegurar a criança, adolescente ou jovem, com absoluta prioridade, respeitando a dignidade da pessoa humana.

No artigo 3o do Estatuto da Criança e do Adolescente, está presente a garantia de todos os direitos fundamentais pertencentes às crianças e adolescentes, sem qualquer tipo de diferenciação.

Os artigos 227 e 229 , trazem os princípios que integram o instituto da adoção, como uma forma de garantir os direitos das crianças e adolescentes.

A Dignidade da Pessoa Humana é um reflexo da Declaração Universal dos Direitos Humanos. E, demonstra sua relevante atribuição do princípio para as crianças e adolescentes, trazendo resguardo dos seus direitos fundamentais e garantindo o que the são essenciais para que possa acontecer um desenvolvimento digno e saudável.

\section{PRINCÍPIO DA AFETIVIDADE}

Este princípio é conceituado por Paulo Lôbo (2012, p. 70-71) da seguinte maneira:

O princípio da afetividade
especializa, no âmbito
familiar, os princípios
constitucionais
fundamentais da
dignidade da pessoa
humana (art. 1o, III) e da
solidariedade (art. 3o, I), e
entrelaça-se com os
princípios da convivência
familiar e da igualdade
entre cônjuges,
companheiros e filhos, que
ressaltam a natureza
cultural e não
exclusivamente biológica
da família.

Percebe-se que o afeto não é explícito na legislação como um princípio, mas podemos entendê-lo, de maneira implícita. 0 artigo 227, $\S 60$ da Constituição Federal traz a equiparação entre os filhos, tanto no quesito social, mas, principalmente, no afetivo. Portanto, a doutrina contemporânea pondera o valor jurídico do afeto, sendo seguido como um princípio geral.

Presentes essas circunstâncias, é onde ocorre a diferença entre pai e genitor. Pai é considerado cria, independentemente de sangue. No outro extremo, o genitor é aquele que dá a vida biologicamente falando.

Nos casos em que o pai não é o genitor, o vínculo afetivo entre a criança e o adulto deve ser priorizado. Assim, esse princípio da afetividade impulsionam a filiação socioafetiva, de forma que o afeto impera sobre biológico, demonstrado pelo julgado trazido do Tribunal de Justiça.

\section{PRINCÍPIO DA IGUALDADE ENTRE FILHOS}

A equiparação de filhos adotivos com os sanguíneos, foi trazida pela Constituição da República Federativa do Brasil (1988) em seu artigo 227, §6ㅇ e pelo Código Civil (2002) no artigo 1596. Entre os doutrinadores, esse princípio ganhou vigor e, hoje em dia, não existe qualquer tipo de diferença entre os filhos.

\section{PRINCÍPIO DA CONVIVÊNCIA FAMILIAR}

Assegurado pela Constituição Federal e reconhecido pelo Estatuto da Criança e do Adolescente em seus artigos 227 e 19, 
respectivamente, garante para a criança e adolescente uma vida com dignidade.

É no âmbito familiar que a criança pode se desenvolver de maneira sadia, e tudo o que forma o seu caráter e personalidade. $\mathrm{Na}$ convivência familiar encontra-se a afetividade, que em razão dela se compõem a entidade familiar, independente de laços biológicos.

A convivência familiar em muitos casos não acontece dentro da família natural por inúmeros motivos, buscando assim, uma família adotiva para que haja integração dessa criança em um âmbito famíliar.

É preferida a família extensa - parentes da criança como tios, primos, avós -, em razão do laço sanguíneo. Contudo, essa procura por parentes, pode prejudicar o menor em seu desenvolvimento saudável, que precisa de um lugar com afeto e proteção, e não lares e casas de parentes desconhecidos que, por vezes, os rejeitam, sendo que uma família "substituta" poderia criar esse laço, garantido o que o ordenamento jurídico visa proteger.

Dessa forma, a criança e adolescente permanece em abrigos por tempo indefinido e superior ao que a lei permite, tendo seus direitos da convivência familiar e dignidade humana feridos. Sendo que, nesse tempo de espera, eles poderiam estar integrados em um âmbito familiar tendo o seu desenvolvimento de forma saudável.

Essa consequência decorre de o instituto da adoção ser usado como uma medida excepcional, quando não se encontra outro caminho para socorrer, o que, muitas vezes, tem como resultado um ato ineficaz por ser tardio.

Maria Berenice Dias (2017, p. 69) faz uma crítica:

Desse modo, nada justifica que, durante anos, crianças e adolescentes sejam mantidos institucionalizados, na vã tentativa de forçar que os pais ou algum familiar se responsabilize por eles. São tão demoradas as tentativas de manter os filhos junto da família natural ou extensa que as crianças crescem nos abrigos, o que lhes subtrai as chances de serem adotadas.
Todo esse período em que as crianças são mantidas em lares de abrigo, a espera que algum familiar o aceite, não ocorrendo a destituição familiar, sem ser inserida em uma entidade familiar e, muito menos na lista de adoção, tem como consequência a consideração dessas crianças como "velhas", cooperando para o crescimento da adoção tardia.

Portanto, o Direito à Convivência Familiar é considerado como representativo da Dignidade da Pessoa Humana, em razão da família ser a maior responsável pelo desenvolvimento da criança, então, todas as crianças e adolescente possuem o direito de crescer no seio de uma família, independentemente de como a família se caracterize, de laços sanguíneos ou afetivos.

\section{RELAÇÕES PRINCIPIOLÓGICA COM O INSTITUTO DA ADOÇÃO}

No processo de adoção, é destacado a Doutrina da Proteção Integral que fazem parte os princípios da Prioridade Absoluta e do Melhor Interesse.

Pela Doutrina da Proteção Integral, crianças e adolescentes possuem seus direitos universalmente conhecidos, não apenas os comuns aos adultos, mas também os direitos especiais em razão de sua condição de desenvolvimento.

Da dignidade da pessoa humana sucede a proteção integral, instituída no país desde a Carta Magna de 1988. Assim, o menor em situação precária deve ter a garantia de proteção pelo responsável, seja a família de origem, a adotiva ou a casa de acolhimento.

No Brasil, por meio da Convenção das Nações Unidas, surgiu o Princípio da Prioridade Absoluta, que se efetivou com a Constituição Federal, no artigo 227 e 40 do ECA (1990), eles entendem como prioridade as necessidades das crianças e adolescentes. Nos âmbitos em que os interesses das crianças estiverem em jogo, às prioridades será sempre ao seu favor. É um princípio que também se vê presente Lei 8.069/1990 no artigo 100, § único, inciso II.

Essa proteção contece em razão de entenderem que a tutela do interesse da criança e do adolescente é relevante para o progresso da nação, considera o fato desses estarem em desenvolvimento, e possuírem a fragilidade de um ser humano em formação. Seu objetivo é efetivar a proteção integral, promovendo uma prioridade que vai viabilizar a garantia dos direitos fundamentais. 
Também foi trazido pela Convenção das Nações Unidas, o Princípio do Melhor Interesse incorpora ao procedimento da adoção o melhor interesse da criança, garantindo seu bem-estar e crescimento em um ambiente sadio.

Esse princípio é uma forma de orientação, indicando a prioridade das necessidades das crianças e adolescentes para interpretar a lei, esclarecer conflitos, e até criar regras.

O Melhor Interesse não se caracteriza por uma definição do julgador do que seria melhor para a criança, mas o que ampara a dignidade do menor da melhor forma possível. Uma exemplo seria uma criança vivendo na rua, mesmo que não seja do seu interesse, acolher em uma instituição é exercer o princípio do melhor interesse.

Também vem da ideia de que a criança e o adolescente necessitam de maior atenção por se encontrarem em uma situação de desenvolvimento. Entretanto, o que podemos observar é o desejo dos adultos valendo-se acima dos das crianças. Nessa toada, Maria Berenice Dias discursa (2017, p.67):

Além de praticamente
inviabilizar a adoção,
continua rendo
privilegiado o interesse
dos adotantes, ao ser
estabelecido que a adoção
é feita de acordo com a
ordem cronológica de
habilitação
disponibilidade de crianças
ou adolescentes
adotáveis.

Conforme já exposto, é importante que a criança seja mantida com sua família biológica. No entanto, precisamos ser sensíveis pra entender o melhor interesse da criança, e a permanência delas em lares com a esperança de que seus pais biológicos os levaram pra casa, criar essa expectativa é cruel para esses menores que necessitam e desejam fazer parte de uma entidade familiar.

\section{ADOÇÃO TARDIA}

Esse é um acontecimento que se dá no instituto da adoção quando o menor possui mais de 3 anos de idade. Sobre a prioridade por uma adoção de bebês menores de 3 anos Lôbo (2011, p. 275) entende que:

Segundo os especialistas, quanto mais cedo é feita a adoção, menor o risco de a criança ter passado por experiências de abandono e sofrimento; consideram que a adoção a partir de 3 anos já é tardia, devendo os candidatos a pais ter acompanhamento especializado.

A preocupação com a adoção tardia é incontestável, pois acredita-se que o menor que passou muito tempo dentro do abrigo se sentindo abandonado, demonstrará mais resistência ao se integrar no âmbito familiar. Crianças mais velhas já possuem uma identidade sendo formada, que muitas vezes não vão de encontro ao que a família deseja.

As crianças que chegam aos abrigos, muitas vezes já estão com uma idade evoluída, e em razão de inúmeros motivos como, a preferência da criança, o preconceito de adotar uma criança "velha", a burocracia do judiciário, e o tempo que se permanece na fila da adoção.

Portanto, ainda que a criança e adolescente possuam uma garantia constitucional, na prática a eficácia não anda junto com esse processo. Se observa, infelizmente, uma maior preocupação com os pretendentes e seus desejos sobre as crianças, deixando de lado o bem-estar do menor.

\section{PREFERÊNCIA DOS CANDIDATOS À ADOÇÃO}

As maiorias dos pretendentes, muitas vezes, se mostram irredutíveis quanto às características da criança, mantendo o padrão de uma criança branca, do sexo feminino, sem irmão, com boa saúde, e menos de 03 anos de idade, de preferência recém-nascido. Esse perfil traçado é a maior consequência do fenômeno da adoção tardia.

E são nessas circunstâncias que a dignidade da pessoa humana da criança e adolescente é ferida, em razão de que o esse perfil traçado é benefício somente para o pretendente, fazendo com que esses menores fiquem à mercê de uma seleção levando em consideração suas características físicas e mentais.

Essa preferência irredutível vem de um preconceito e aparência social sobre a adoção de uma criança mais "velha" e daquelas que possuem deficiências. Além disso, gera uma lentidão no processo de adoção, já que existe 
uma lista de habilitação e uma ordem a serem respeitadas.

Ainda existem casos em que os requerentes que estão há muito tempo na fila de espera, sem ter o seu pedido acolhido acabam escolhendo as crianças fora do perfil que desejam, como uma maneira de pôr fim à processo de adoção. Portanto, isso pode ser nocivo as partes, a criança que vai se sentir rejeitada, e os pais que estarão frustrados, podendo resultar em uma entrega do menor para o abrigo.

A questão do judiciário também é um ponto que contribui para a lentidão do processo da adoção, afetando as crianças que possuem as características desejadas, mas por conta de tamanha burocracia e demora se tornam "velhas" demais para serem adotadas.

\section{ASPECTOS POSITIVOS}

Verifica-se que houve uma evolução primordial e positiva, em que o instituto da adoção passou de um processo para satisfazer famílias que desejavam dar continuidade na linhagem, não se preocupando com os interesses das crianças, para um lugar em que o menor se tornou a prioridade do processo, buscando o seu melhor interesse, a proteção integral, a convivência familiar, assegurando seus direitos fundamentais garantidos por lei e buscando uma maior agilidade nos processos.

O Estado não mais tenta se livrar das obrigações de cuidar desses menores, mas se preocupa em encontrar maneiras de proporcionar dignidade a essas crianças e adolescentes.

Além das preocupações em satisfazer os direitos das crianças e adolescentes, campanhas são criadas para garantir maior efetividade, por exemplo, a campanha criada pelo Tribunal de Justiça do Espírito Santo (TJES), com o nome de "Esperando por Você", em apresentação do projeto se diz:

Esperando Por Você visa mudar o futuro de crianças e adolescentes que vivem há anos em instituições de acolhimento do Espírito Santo, especificamente as crianças mais velhas, os grupos de irmãos e aquelas que possuem alguma condição especial de saúde.
Outra campanha é o projeto "Adoção Tardia", que nasceu na Universidade Federal do Rio Grande do Sul (UFRGS). Eles têm como objetivo fazer vídeos das crianças, especialmente as com idade mais avançadas e mostrar os benefícios da adoção.

Contudo, se percebe que muito foi feito e tem sido feito em prol do instituto da adoção, para dar continuidade à evolução deste tão importante instituto jurídico.

\section{ASPECTOS NEGATIVOS}

Diante do exposto, alguns aspectos negativos também foram citados como a preferência pelo recém-nascido, que se dá em razão de uma crença de que a adaptação será mais pacífica, tendo mais facilidade de habituarse conforme a estrutura da família adotante. Além de que, acreditam que as chances de superação dos traumas vividos serão maiores, em razão da criança mais "velha" já ser considerada com uma maior noção de mundo e dos acontecimentos que a sucedem, carregando assim uma bagagem.

Outra questão presente na preferência pela adoção de recém-nascido, está na possibilidade de manter o sigilo, em razão de existir preconceito para as crianças que são adotadas, e ainda mais consideradas "velhas".

Outro ponto que deve ser considerado como um mito na adoção tardia é o temor dos pretendentes que quando a criança crescer, venham a rejeitá-los e decidirem ir atrás da sua família biológica.

Existe uma falsa crença de que marginalidade é algo sanguíneo, passível de ser geneticamente passado aos filhos, ou seja, a criança adotada que veio de um lar nessas condições e possuem um desagradável histórico, aumentando a rejeição dessas crianças.

Dessa forma, percebe-se que o foco da adoção é sempre o interesse e bem-estar dos pretendentes, deixando de lado o melhor interesse da criança.

Além desses aspectos negativos sociais, existem os relacionados ao judiciário. Entre eles, a lentidão do processo da adoção, começando pela destituição do poder familiar e o processo demorado de esgotar as possibilidades da criança continuar com um familiar de laço sanguíneo, chegando a uma idade que os pretendentes não desejam mais adotá-las. 
A demanda da adoção hoje em dia é muito grande, o que muitas vezes, pode gerar a necessidade de mais profissionais, causando um déficit de equipes para prover um célere andamento, colaborando para que esse processo seja lento.

Muito mais da necessidade de haver uma melhora nessa burocratização, também é preciso haver uma conscientização dos pretendentes, para mostrar que a criança sem o perfil desejado, também são capazes de amar, serem amadas e construirem vínculos afetivos. Elas possuem uma maior deficiência emocional, mas que pode ser suprida se os pretendentes estiverem preparados pra enfrentar essa jornada com amor e não com temor. Esse é um processo definitivo, eles precisam estar seguros que realmente desejam adotar e pronto para lidar com os obstáculos do caminho.

Assim, quanto mais lento o processo da adoção, por mais tempo a criança e adolescente vão permanecer em lares, podendo impossibilitar uma futura adoção.

É plausível a preocupação da legislação em proibir o contato, mas poderia ser pensado em haver uma apresentação inicial. Pois o vínculo afetivo, essencial para a adoção, não se dá por meio de características físicas e qualidades genéricas, mas existe um requisito subjetivo que a letra da lei não consegue alcançar por meio de um cadastro de preferências.

Em relação ao nosso ordenamento jurídico, mesmos com tantas modificações e inovações, ainda é procedido como um fenômeno excepcional. Podemos pensar em recomendações, como o cumprimento dos prazos; aumentar o diálogo entre os profissionais envolvido; melhorar os cursos para os pretendentes; diminuir a persistência na procura da família biológica; inovar com a criação de uma vara especializada. Esses exemplos poderiam servir como uma maneira de agilizar os processos e solucionar conflitos que surgem a todo o momento.

\section{CONSIDERAÇÕES FINAIS}

Diante de tudo o que foi exposto, não se pode desmerecer a evolução que o nosso ordenamento jurídico teve em relação ao instituto da adoção, pois há tempos atrás era usado apenas como uma maneira de dar continuidade para a linhagem de determinada família. Mas, hoje em dia, é o meio pelo qual garante o desenvolvimento digno, com afeto, assegurando a convivência familiar e diminuindo as crianças que não possuem um lar e ficaram desamparadas, com todos os esforços para o melhor interesse da criança e adolescente.

Do modo em que o pensamento foi sendo apresentado, chegamos ao fenômeno da adoção tardia, onde se encontram a maioria das crianças, atualmente, aptas a serem adotadas. Por meio de autores e pesquisas, o fato mais preocupante foi o delas se integrarem ao processo da adoção já com idade considerada "velha", por muitos motivos e um deles ser a lentidão do judiciário; e os pretendentes serem resistente quanto ao perfil traçado por eles, causando desequilíbrio entre as crianças habilitadas para serem adotadas e o número das pessoas que desejam adotar.

Uma mudança de mentalidade por meio de políticas públicas deveria ser inserida na sociedade com muito vigor para que fosse quebrado a ideia mal construída sobre as crianças mais velhos, e a necessidade de demonstrar ativamente sobre a afetividade e seu importante papel como protagonista da adoção. Contudo, também deveria haver um maior incentivo do Estado, pois Ele é um dos grandes responsáveis por garantir os direitos fundamentais da criança, pois esses menores possuem direito à um lar, a uma família, não carecendo de permanecer toda sua infância e adolescência em lares e abrigos.

Para concluir, a dignidade da pessoa humana deve ser sempre uma prioridade, garantida uma vida digna e saudável par que a criança e adolescente se desenvolvam cheios de amor, afeto, segurança. E a adoção tardia deve ser entendida como uma representante de tudo isso dito, do amor, do afeto, e não como uma adoção problemática, mas sabendo que são essas decisões de adotar que vão salvar inúmeras crianças e adolescentes de passarem toda a sua vida sem saberem o que significa 'ser família'.

\section{REFERÊNCIAS}

Adoção Tardia. 2019. Disponível em: <https:// www.adocaotardia.com/>. Acesso em: 02 jun 2020.

BRASIL. Constituição (1988). Constituição da República Federativa do Brasil. Brasília, DF: Senado Federal, 1988.

BRASIL. Presidência da República. Lei n. 10.406, 10 de janeiro de 2002. Institui o Código Civil. 
Diário Oficial da União, Brasília, DF, 11 jan. 2002. Disponível em: http://www.planalto.gov.br/ccivil_03/Leis/2002/ L10406compilada.htm. Acesso em: 10 nov. 2019.

BRASIL. Presidência da República. Lei n. 6.697, de 10 de outubro de 1979. Institui o Código de Menores. Brasília, 1979. Disponível em: http://www.planalto.gov.br/ccivil_03/leis/19701979/L6697.htm Acesso em: 07 nov. 2019.

BRASIL. Presidência da República. Lei no 8.069, de 13 de julho de 1990. Dispõe sobre o Estatuto da Criança e do Adolescente e dá outras providências. Diário Oficial. Brasília, 13 de julho de $1990 . \quad$ Disponível em: http://www.planalto.gov.br/ccivil_03/leis/L8069. htm. Acesso em: 07 de nov. 2019.

DIAS, Maria Berenice. Filhos do Afeto: questões jurídicas. 2. ed. São Paulo: Revista dos Tribunais, 2017.

DIAS, Maria Berenice. Manual de direito das famílias. 4. ed. São Paulo, Revista dos Tribunais, 2016. E-book.

DINIZ, Maria Helena. Curso de Direito Civil Brasileiro: direito de Família. 25. ed. São Paulo: Saraiva, 2010. v. 5.

Esperando por Você. Tribunal de Justiça do Estado do Espírito Santo. Disponível em: <http:// www.tjes.jus.br/esperandoporvoce/>. Acesso em: 02 jun. 2020.

GONÇALVES, Carlos Roberto. Direito civil brasileiro: direito de família. 11. ed. São Paulo: Saraiva, 2014. v. 6.

LÔBO, Paulo Luiz Netto. Direito Civil: famílias. 4.ed. São Paulo: Saraiva, 2011.

MARCÍLIO, Maria Luiza. História social da criança abandonada. São Paulo: Hucitec, 1998. Disponível em: <https://www.scielo.br/ scielo. php?script=sci_arttext\&pid=S0102-01881999000 100014>. Acesso em: 20 nov. 2019.

MORAES, Alexandre de. Constituição do Brasil Interpretada. 5. ed. São Paulo: Atlas, 2005. p. 129.
SOUZA, Radindranath Valentino A. Capelo de. A adoção: constituição da relação adoptiva. Coimbra: 1973. p. 15 e 16.

TJ-SP - AC: 100326049220178260236 SP 1003260-49.2017.8.26.0236, Relator: Fernando Torres Garcia (Pres. Seção de Direito Criminal), Data de Julgamento: 17/10/2019, Câmara Especial, Data de Publicação: 17/10/2019. 